\title{
Construction of Logistic Information System of Xinjiang Characteristic Fruits Based on Quick Response
}

\author{
Ying Xu' ${ }^{1}$, Liwei Bao ${ }^{1}$, Yu Zhang ${ }^{2}$, Nengbin Xie ${ }^{2}$ \\ ${ }^{1}$ Business School of Zhejiang University City College, Hangzhou, China \\ ${ }^{2}$ Xinjiang Fruit Group Co. LTD, Urumchi, China \\ Email: xuying@zucc.edu.cn, baolw@zucc.edu.cn, 236801348@qq.com, 904581298@qq.com
}

How to cite this paper: Xu, Y., Bao, L.W., Zhang, Y. and Xie, N.B. (2017) Construction of Logistic Information System of Xinjiang Characteristic Fruits Based on Quick Response. Open Journal of Social Sciences, 5, 84-89.

https://doi.org/10.4236/jss.2017.510008

Received: July 26, 2017

Accepted: October 10, 2017

Published: October 13, 2017

\begin{abstract}
This paper presents a design of logistic information system of Xinjiang characteristic fruits which is studied from the perspective of consumer experiences; it aims to provide quick response to customers. The main advantages of this system are to integrate online and offline information, implement the whole industry chain traceability system and integrate advanced digital technologies.
\end{abstract}

\section{Keywords}

Logistic Information System, Quick Response, Xinjiang Characteristic Fruits

\section{Introduction}

Xinjiang province is one of main producing areas of characteristic fruits in China, and has a solid foundation and distinct advantages in fruit industry. However, compared to similar or competing products in other provinces, the competitive advantages of fruits in Xinjiang are influenced and weakened because of higher-cost of logistic and longer delivery time due to its remote location. With the increasing of new marketing patterns, such as on-line sales and mobile commerce, logistics distribution has become more important in the development of Xinjiang characteristic fruits industry and been concerned widely.

Quick responses from sellers have become the basic requirement of customers when they decide to make a purchase. To ensure market competitiveness and improve the consumption experience, the construction of logistic information system of Xinjiang characteristic fruits needs to be based on logistics needs of customers, which can provide rapid response to customers in the process of 
purchase, including post-purchase stage.

\section{Review of Studies on Quick Response and Logistic System}

Quick response was originated in the textile and clothing industry of the United States in the 1980s; it involves a series of measures taken by supply chain managers to shorten delivery time of goods, and aims to increase their profits by matching demands and supplies more efficiently [1]. "Quick response to orders production system" or in brief "quick response production system (QRPS)" was studied widely in production system in various industries [2], such as textiles, clothing and footwear [3], nowadays also applied in urgent relief and libraries and museums [4] [5]. In the earlier years, quick responses were focused on optimal ordering and inventory management to enable retailers to estimate customer demand more accurately, and improve stocking decisions for products with uncertain demand [6] [7] [8]. In recent years, new information technologies including quick response codes were discussed and applied in construction of quick response system [9] [10].

However, studies on quick response in customer experience just started. Kiane investigated how quick responses and coupons jointly impact consumer behavior [11]. Researchers began to focus on the relationship of customer, especial strategic customer and quick response [12] [13].

There are also many research results about logistic system. Numerous studies focus on the strategies and technologies of logistic system, besides the construction of logistic information system. In general, a study on logistic of agricultural products based on quick response seems little. This paper presents a design of logistic information system from the perspective of customers, who would eager to know the quality, origin and distribution of products instinctively when they make purchases.

\section{Overall Architecture of Logistic Information System of Xinjiang Characteristic Fruits}

Logistic information system of Xinjiang characteristic fruits was built on the basis of integrated cooperation platform of logistics, storages and distribution, which aims to realize three objectives. The first is order fulfillment of e-commerce on-line sales; the second is to support the quick response of logistics for offline marketing channels. The third is to develop business in international market. All business-managements are serviced for quick response of sellers.

For ordering information from e-commerce, platform will finish order distribution and composition according to relevant target regions and give orders to logistics centers in various regions to execute and finish the distribution by the third party logistics. Logistics centers should provide demand forecasting in their regions to total warehouse in Urumchi and finish inventory replenishment. This is called as order driven storage and distribution operation mode.

For offline marketing channels, such chain stores, franchisees and supermar- 
kets, the platform also helps to short leading time and improve distribution services, which also needs to send orders to total warehouse in Urumchi to finish inventory replenishment. This is another operation mode of storage and distribution based on safe inventory control.

On the basis of construction of integration logistics platform above, relevant logistics information system was designed and applied, which could help to support the quick response of e-commerce marketing and offline distribution channels effectively. The overall architecture of logistic information system of Xinjiang characteristic fruits is listed as below (Figure 1).

\section{Advantages of Logistic Information System of Xinjiang Characteristic Fruits}

\subsection{Integrate Online and Offline Information and Data}

In this system, all information would be integrated from various databases, where are numerous data produced from different activities. Thus online and offline sales volume can be collected in a system and consumer can choose different ways to realize the products synchronously, the information provided online is consistent with offline stores.

\subsection{Implement the Whole Industry Chain Traceability System}

Logistic information system can help to collect various information and data produced in the each stage of whole industry chain. Take Xinjiang Fruit Group as an example, it has implemented the whole industry chain sales model, that is,

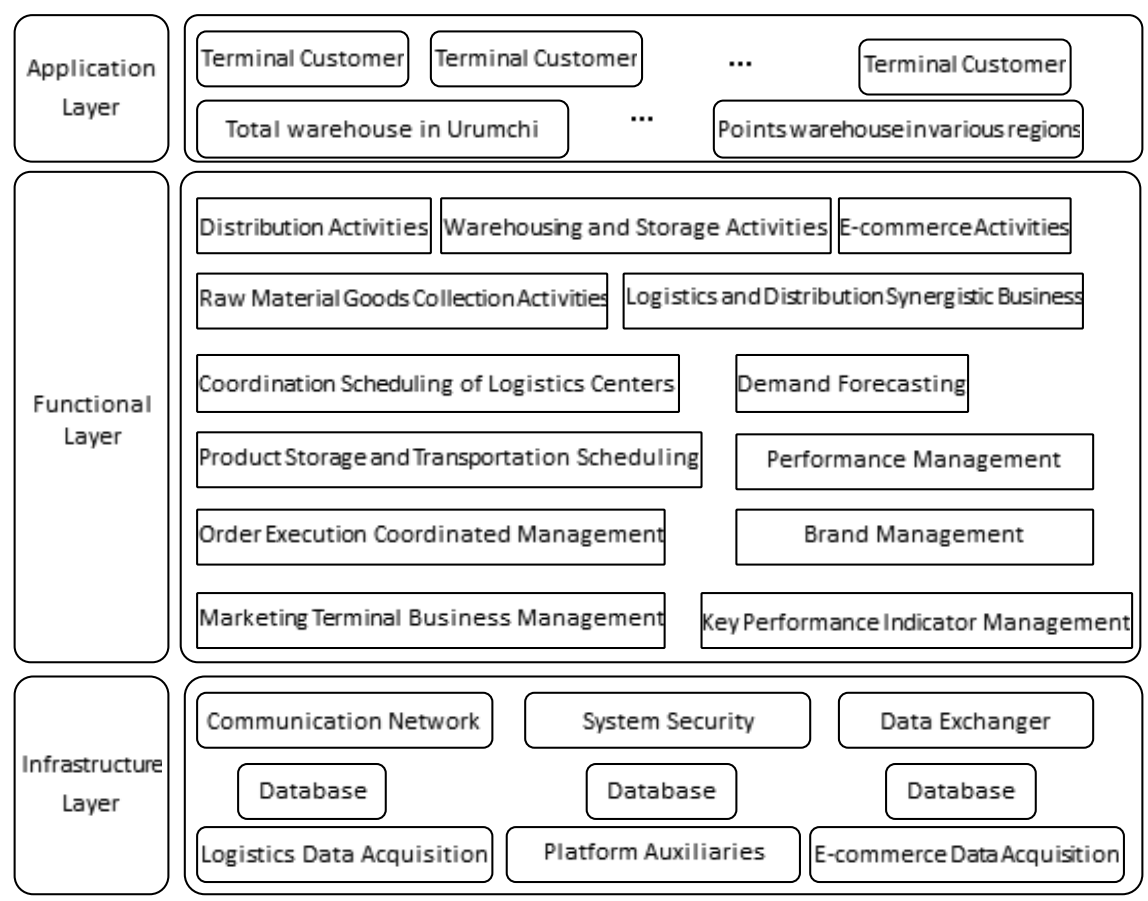

Figure 1. Overall architecture of logistic information system of Xinjiang Characteristic fruits. 
information system is run through the whole process of supply chain of characteristic fruits and helpful to performance online and offline sales effectively. This model is consumer-orientated, which starts from the source of industrial chain, and goes through the different stages including planting and purchasing, materials processing, distribution and logistics, brand promotion, and finally forms the traceability system of characteristic fruits safety. Figure 2 shows the implementation of traceability system in packing workshops.

\subsection{Enhanced Integration of Digital Technologies}

On the basis of the original technology, lots of new information services in this information system are increased and included for customers, such as product traceability system based on QR codes, instant query system of delivery service and information push system of characteristic fruits. After customers place orders, they can inquiry transportation route, arrival time of products, which is beneficial to track the express items and keep themselves informed of logistics dynamic.

Package data have been integrated in the system as well. Customers can inquiry the information of specification, content and quantity of packing, which can help them to choose more Cost-effective products.

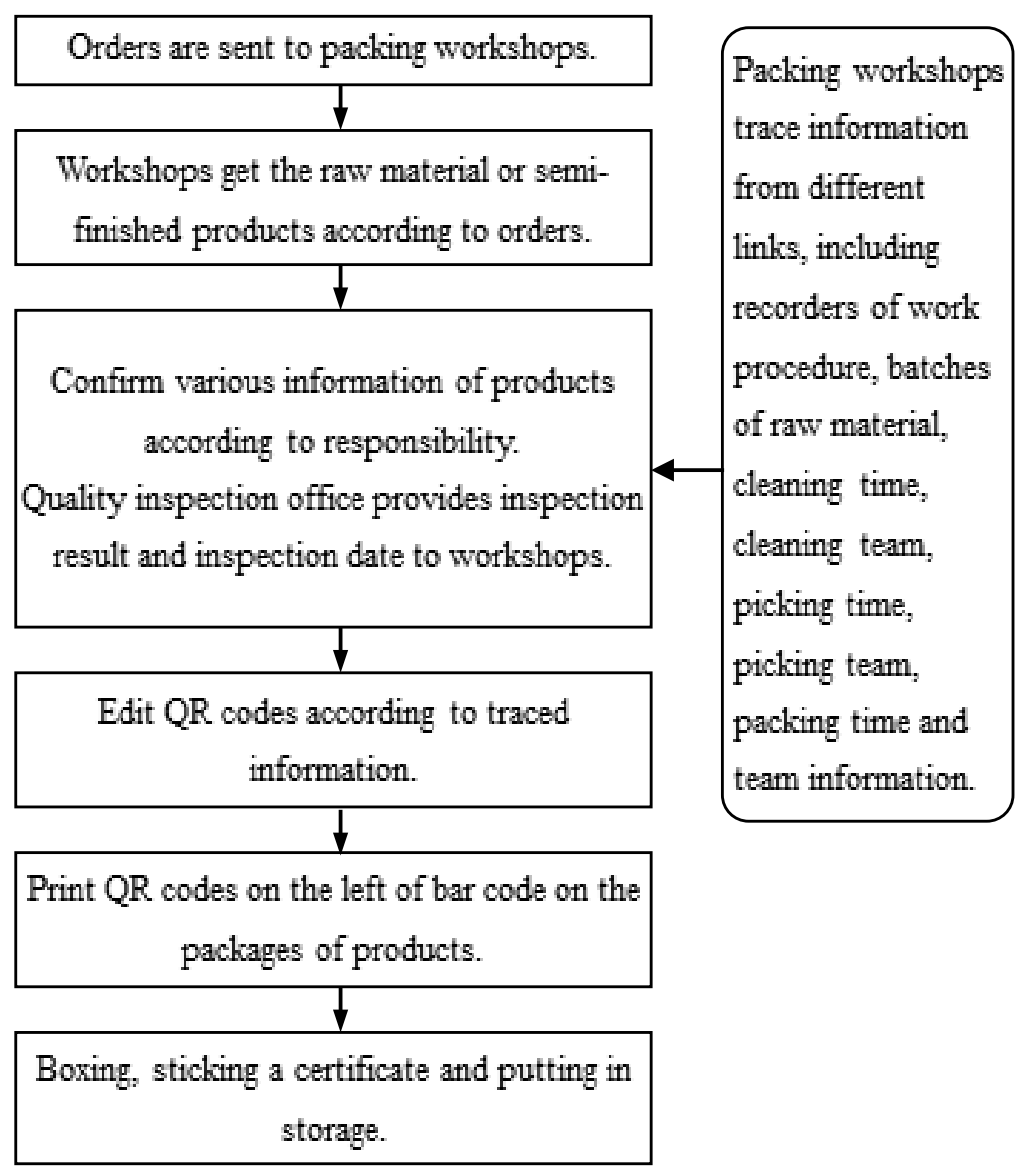

Figure 2. The implementation of QR codes traceability system in packing workshops. 
Another example is the upgrading of QR codes. Not only the contents of traceability system have been increased, information of at least six different production stages about characteristic fruits can be traced, but also the technology of QR codes has been developed. Instead of being pasted by workers, today QR codes are direct printed on the packages, that means the constant $Q R$ codes has taken the place of variable QR codes and traceability system also needs to be upgraded to meet requirements.

\section{Conclusions}

In modern society, more and more consumers devote much attention to experience in the process of purchase. Improving consumption experiences is an important issue for agricultural products, especially for Xinjiang characteristic fruits because of it remote location. The design of logistics information system in this paper is studied from the perspective of customers, which provides various information to customers as far as possible by upgrading technologies and integrating data. In addition, support conditions, such as operation standard and performance management also need to be constructed to get better results.

An internal analysis report in Xinjiang Fruit Group showed that the main influence factors of purchasing characteristic fruits are word-of-mouth recommendations and promotion activities. Logistics that was the biggest complaints seems to be out of sight gradually. It shows that the construction of logistics of Xinjiang characteristic fruits is improving consumption experiences and improving satisfaction.

\section{Acknowledgements}

This research was financially supported by National 12th five-year science and technology support program of China (2015BAD29B03).

\section{References}

[1] Sunil, C. and Peter, M. (2003) Supply Chain Management Strategy, Planning and Operation. 2th Edition, Social Sciences Academic Press, Beijing.

[2] Kuroda, M. and Takeda K. (1998) General Structure and Characteristics of Quick Response Production System. Computers \& Industrial Engineering, 35, 395-398. https://doi.org/10.1016/S0360-8352(98)00117-X

[3] Marcia, P., Amrik, S.S. and Peter R. (1999) Quick Response Supply Chain Alliances in the Australian Textiles, Clothing and Footwear Industry. International Journal of Production Economics, 62, 119-132. https://doi.org/10.1016/S0925-5273(98)00224-2

[4] Sheu, J.-B. (2007) An Emergency Logistics Distribution Approach for Quick Response to Urgent Relief Demand in Disasters. Transportation Research Part E: Logistics and Transportation Review, 43, 687-709. https://doi.org/10.1016/j.tre.2006.04.004

[5] Michelle, K.S. (2013) A Case Study on the Appropriateness of Using Quick Response (QR) Codes in Libraries and Museums. Library \& Information Science Research, 35, 207-215. https://doi.org/10.1016/j.lisr.2013.03.002 
[6] Doğan, A.S. (2009) Optimal Ordering and Pricing in a Quick Response System. International Journal of Production Economics, 121, 700-714. https://doi.org/10.1016/j.ijpe.2009.04.020

[7] Hsiao, Y.C. (2008) Integrated Logistic and Inventory Model for a Two-Stage Supply Chain Controlled by the Reorder and Shipping Points with Sharing Information. International Journal of Production Economics, 115, 229-235. https://doi.org/10.1016/j.ijpe.2008.06.004

[8] van Wijk, A.C.C., Adan, I.J.B.F. and van Houtum, G.J. (2013) Optimal Allocation Policy for a Multi-location Inventory System with a Quick Response Warehouse. Operations Research Letters, 41, 305-310. https://doi.org/10.1016/j.orl.2013.03.002

[9] Seda, D., Ramazan, K. and Kadir A.D. (2015) Usage Level and Future Intent of Use of Quick Response (QR) Codes for Mobile Marketing among College Students in Turkey. Procedia-Social and Behavioral Sciences, 181, 405-413. https://doi.org/10.1016/j.sbspro.2015.04.903

[10] Yeong, G.K. and Eunju, W. (2016) Consumer Acceptance of a Quick Response (QR) Code for the Food Traceability System: Application of an Extended Technology Acceptance Model (TAM). Food Research International, 85, 266-272. https://doi.org/10.1016/j.foodres.2016.05.002

[11] Kiane, G., Adilson, B. and Jean C.C. (2013) Should Retailers Pay to Bring Customers Back? The Impact of Quick Response and Coupons on Purchase Outcomes. Journal of Business Research, 66, 665-669. https://doi.org/10.1016/j.jbusres.2012.02.042

[12] Zhao, R.X., Kou, Y.T., Xian, G.J. and Mao, G.W. (2010) Study on Technologies for Information Monitoring and Quick Response of Agricultural Focuses and Significant Events. Agricultural Sciences in China, 9, 764-770. https://doi.org/10.1016/S1671-2927(09)60153-X

[13] Yang, D.J., Qi, E.S. and Li Y.J. (2015) Quick Response and Supply Chain Structure with Strategic Consumers. Omega, 52, 1-14. https://doi.org/10.1016/j.omega.2014.10.006 